\title{
A preoperative risk classifier that predicts tumor progression in patients with cranial base chondrosarcomas
}

\author{
Andrew S. Venteicher, MD, PhD, ${ }^{1,3}$ Michael M. McDowell, MD, ${ }^{1}$ Ezequiel Goldschmidt, MD, PhD, ${ }^{1}$ \\ Eric W. Wang, MD, ${ }^{2}$ Carl H. Snyderman, MD, MBA, ${ }^{2}$ and Paul A. Gardner, MD ${ }^{1}$ \\ Departments of ${ }^{1}$ Neurological Surgery and ${ }^{2}$ Otolaryngology, University of Pittsburgh Medical Center, Pittsburgh, Pennsylvania; \\ and ${ }^{3}$ Department of Neurosurgery, University of Minnesota, Minneapolis, Minnesota
}

\begin{abstract}
OBJECTIVE The authors conducted a study to identify clinical features of cranial base chondrosarcomas that will predict tumor progression after resection.

METHODS The authors performed a retrospective study at a tertiary referral cranial base center. Patients who underwent resection of cranial base chondrosarcomas between January 2004 and December 2018 were followed longitudinally. The main outcome measure was progression-free survival (PFS).

RESULTS A total of 41 patients were treated for histopathologically proven "conventional" cranial base chondrosarcomas during the study period, and the median PFS was 123 months for the cohort. Univariate analysis was performed on clinical, anatomical, and radiographic parameters collected for each patient. Features that were statistically significant were fed into a multivariate regression model, which revealed two independent predictors of PFS: patient age and encasement of 3-4 major arteries (> $25 \%$ of the vessel wall surrounded by tumor). Using these two variables of age and multiple arterial vessel encasement, the authors generated a risk stratification model using a simple point system to predict PFS in patients with cranial base chondrosarcomas. Based on these two factors known preoperatively, this model could stratify patients into high-risk ( $10 \%$ of patients), intermediate-risk ( $68 \%$ of patients), and low-risk ( $22 \%$ of patients) subgroups corresponding to dramatically distinct median PFS (1.8 years, 10.2 years, and no progression, respectively).

CONCLUSIONS In patients with cranial base chondrosarcomas, age and artery encasement are variables known preoperatively that can powerfully predict tumor progression, define operative goals, and aid in selecting postoperative adjuvant therapy.
\end{abstract}

https://thejns.org/doi/abs/10.3171/2019.10.JNS191672

KEYWORDS chondrosarcoma; petroclival junction; skull base; progression-free survival; arterial encasement; endoscopic endonasal approach; oncology

$\mathrm{C}$ HONDROSARCOMAS comprise a heterogeneous group of malignant bone tumors marked by varied outcomes for patients. ${ }^{18}$ It remains difficult to predict those patients whose tumors will adopt an aggressive clinical behavior. Chondrosarcomas represent the second most common primary bone cancer, accounting for approximately $25 \%$ of malignant bone tumors ${ }^{6}$ which may occur in a variety of locations along the axial or appendicular skeleton. ${ }^{27,28}$ Head and neck chondrosarcomas constitute $5 \%-12 \%$ of cases $^{4,14,24}$ diagnosed at a mean age of 40-47 years ${ }^{1,4}$ For tumors arising at the cranial base, the involvement of critical neurovascular structures causes patients to present with cranial nerve palsies and/or symptoms due to brainstem compression. . $^{19,25,30}$

The treatment of cranial base chondrosarcoma remains challenging due to the tumor's deep location and intimate anatomical relationships with the brainstem, major arteries, and cranial nerves. The treatment strategy often involves maximal resection with or without postoperative high-dose radiation therapy, as chondrosarcomas are classically radioresistant. ${ }^{12,31,32}$ At present, chemotherapeutic options are only investigational, since chondrosarcomas do not typically exhibit sensitivity to current drug strategies. $^{12}$

ABBREVIATIONS EEA = endoscopic endonasal approach; PFS = progression-free survival.

SUBMITTED June 15, 2019. ACCEPTED October 22, 2019.

INCLUDE WHEN CITING Published online January 10, 2020; DOI: 10.3171/2019.10.JNS191672. 
Maximal resection provides significant potential for survival benefit, but it also poses the risk of neurological morbidity. This dichotomy has created a vital need to find prognostic factors that may be useful for preoperative surgical planning. Because cranial base chondrosarcomas are uncommon and make up only $6 \%$ of cranial base tumors, ${ }^{11}$ such factors have not yet been reported. To this end, we studied the experience at our institutional Center for Cranial Base Surgery to define preoperative variables that could prognosticate tumor recurrence in these patients.

\section{Methods \\ Patient Cohort}

A retrospective analysis at the University of Pittsburgh from January 2004 to the end of December 2018 was performed and approved by our institutional review board. Patients who underwent open microsurgical or endoscopic endonasal approaches (EEAs) for histopathology-proven cranial base chondrosarcomas were identified through the electronic medical record system. Recorded parameters included patient demographics (age at diagnosis, sex), surgical details (approach, extent of resection), anatomical location of the tumor (anterior fossa/orbit, cavernous sinus, posterior clinoid, sublacerum region), pathology features (chondrosarcoma subtype, grade, Ki-67 percentage), and parameters on MRI (size as maximum [axial, coronal, or sagittal] diameter, gadolinium enhancement, intradural extension, number of major arteries encased). Major arteries were defined as the internal carotid arteries, basilar artery, and vertebral arteries. Chondrosarcoma subtypes were diagnosed by neuropathology as "conventional," mesenchymal, and extraskeletal myxoid variants. None were the dedifferentiated subtype. Major arteries included the internal carotid arteries, basilar artery, and the vertebral arteries. Arterial encasement was defined as cases in which the tumor was in contact with at least $25 \%$ of the vessel wall. The extent of resection was calculated by comparing T2-weighted sequences (and postcontrast T1-weighted images, when appropriate) of the preoperative MRI study and first postoperative MRI study at 3-6 months. Time to progression was defined as the interval between the date of surgery at our institution and either symptomatic or asymptomatic radiological tumor growth. Progression was defined as a minimum 3-mm growth on T2-weighted and/or postcontrast T1-weighted sequences. Eight of 43 patients ( 7 of 41 patients with conventional chondrosarcomas) underwent treatment elsewhere prior to referral to our institution. For these patients, progression was measured from the time of surgery at our institution, since the initial resection at the outside facility was often a partial debulking only. The tumor grade was determined in most but not all patients (37 of 41 patients with conventional chondrosarcoma).

\section{Statistical Analysis}

Statistical analysis was performed using $\mathrm{R}$ software version 3.53 with an RStudio interface. The survival package version 2.43-3 and survminer package version 0.4.3 were used for survival analysis and graphic visualization.
Survival curves were plotted using the ggsurvplot() function. PFS was the main outcome measure. The KaplanMeier method was used to estimate survival probability from the observed survival in our cohort. Log-rank tests were used to compare two or more survival curves. Cox proportional hazards models were used for multivariate regression analyses. In the univariate regression, variables that met a $p$ value $<0.1$ were selected for multivariate analysis. Age was treated as a continuous variable in regression analyses. Only those variables in multivariate regression analysis that met a $p$ value of $<0.05$ were determined to be statistically significant.

\section{Results \\ Patient Cohort}

From 2004 to 2018, 43 patients underwent resection of cranial base chondrosarcomas. Based on histopathological diagnosis, 41 patients had conventional chondrosarcomas, 1 patient had an extraskeletal myxoid chondrosarcoma, and 1 patient had a mesenchymal chondrosarcoma. Because these nonconventional subtypes are known to have different clinical behavior from that of conventional chondrosarcoma, ${ }^{5,15,16,23}$ we limited our analysis to the 41 patients with conventional chondrosarcomas to ensure a more homogeneous population for further study (Fig. 1A, Table 1).

In this cohort of 41 patients with conventional chondrosarcomas, the mean age was 51.5 years, $63.4 \%$ were female, and the mean follow-up duration was 53 months (median of 36 months). The initial surgical management utilized an EEA alone in 39 patients (95.1\%) and a staged open microscopic followed by an EEA approach in 2 patients $(4.9 \%)$ to maximize resection (Table 1). Twelve patients progressed and 5 patients died during the study period (Table 1). PFS at 3 and 10 years was $82.4 \%$ and $57.9 \%$, respectively. Overall survival at 3 and 10 years was $89.6 \%$ and $80.2 \%$, respectively (Fig. 1B and C, Table 2).

\section{Factors Associated With Tumor Progression}

We first tested whether variables associated with tumor progression in case of appendicular and axial chondrosarcoma were prognostic in our cranial base chondrosarcoma cohort. We began by grouping patients according to age. This cohort had two peaks with respect to age, with an inflection point around 35 years (Fig. 2A). When we compared Kaplan-Meier survival estimates of patients < 35 years of age and patients $\geq 35$ years of age in our cohort, we found strikingly that no patients $<35$ years experienced disease progression, whereas those $\geq 35$ years had a median PFS of 8 years ( $p=0.015)$ (Fig. 2B). This is in keeping with prior studies of chondrosarcoma in other areas of the body for which there is an inverse relationship between patient age and survival..$^{1,2,8,13,18}$ Of note, the mean follow-up duration for patients $<35$ years of age was adequate (73.5 months) when compared to that in those $\geq 35$ years of age (52.7 months).

We next asked whether the extent of resection was associated with tumor progression in this cohort. We found that $61 \%$ of patients had a gross-total resection, and $90 \%$ of patients had at least a $90 \%$ tumor resection (Supplemen- 
A

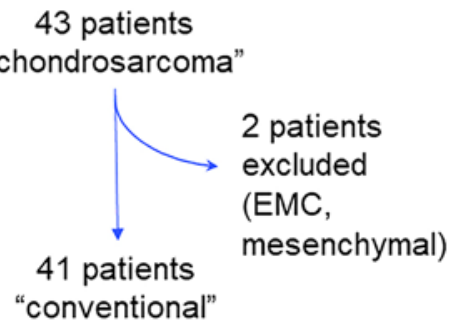

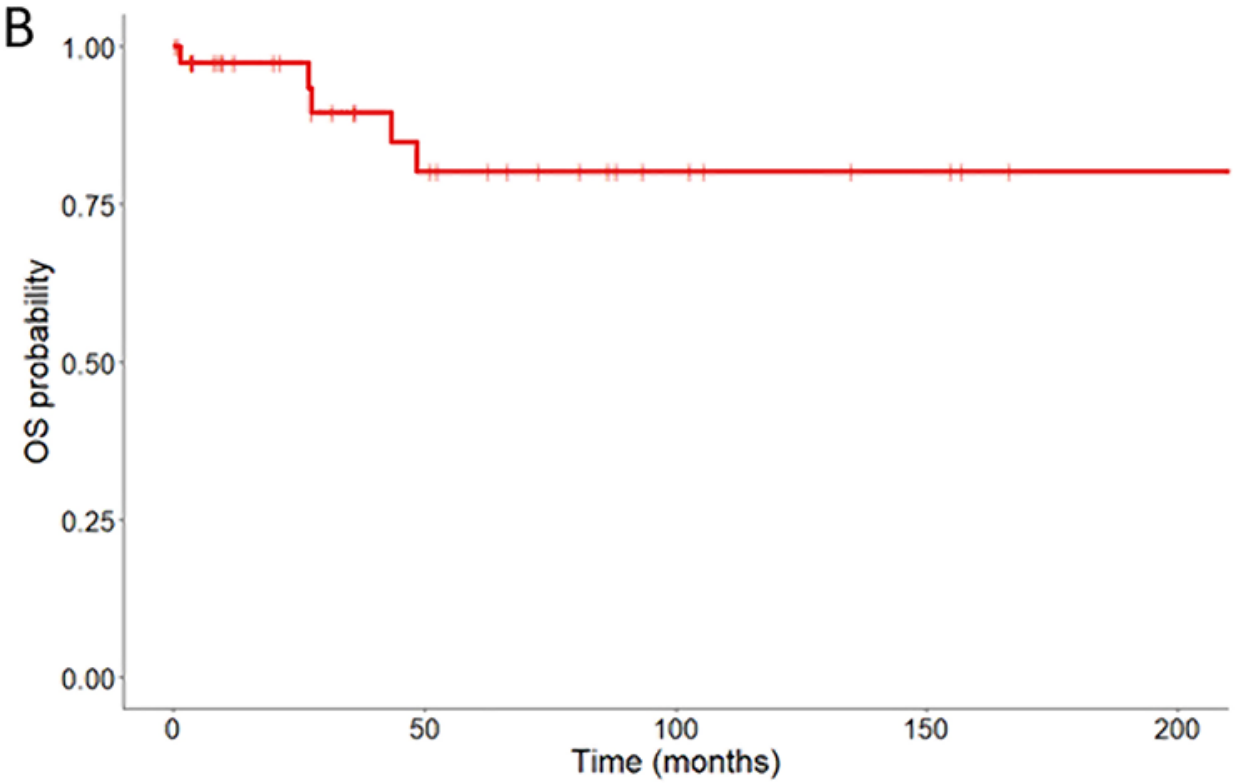
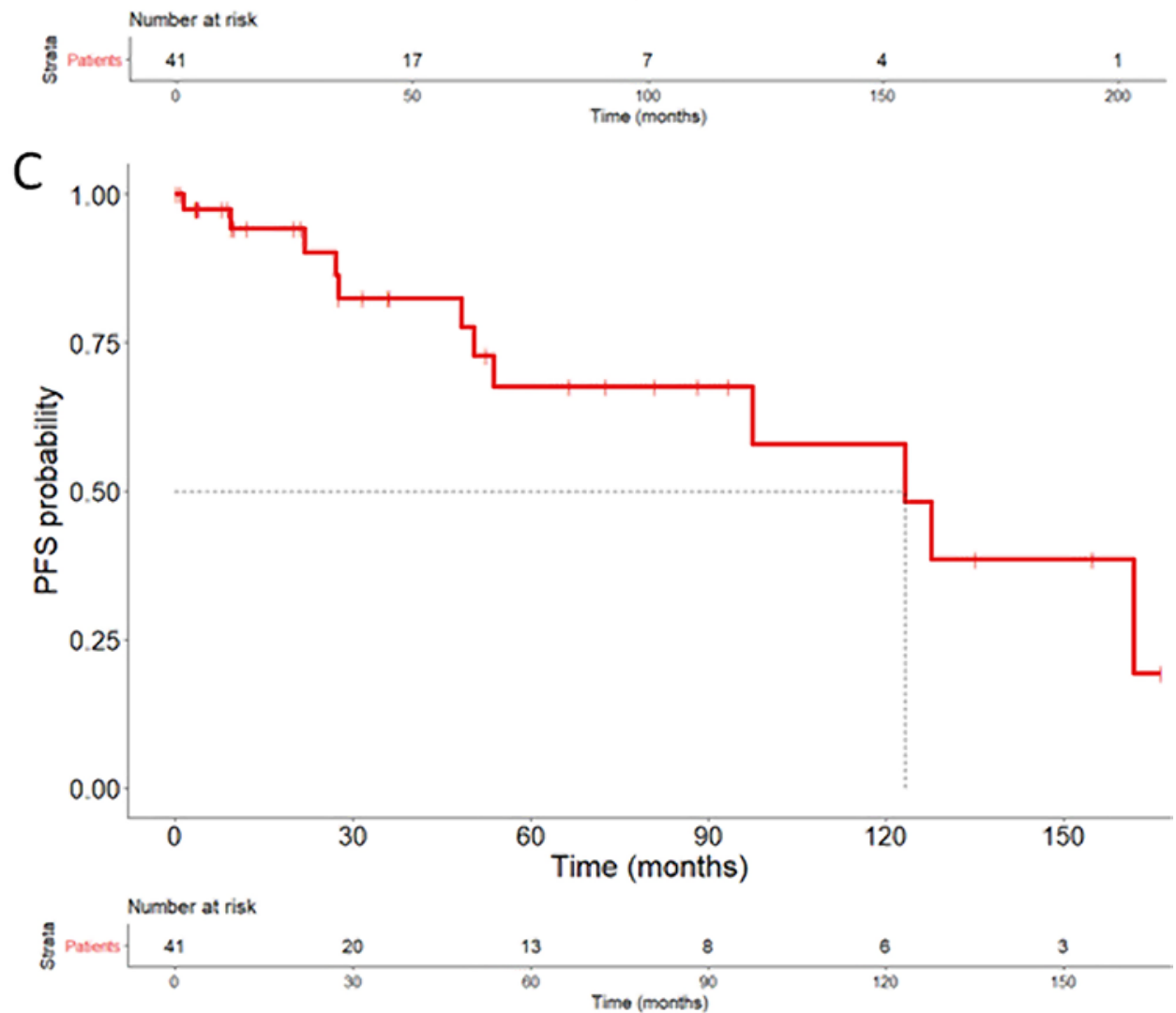

FIG. 1. Cohort of patients with cranial base chondrosarcomas. A: Two patients were excluded for having chondrosarcoma variants that have distinct clinical behavior. B and C: Kaplan-Meier curves of overall survival (B) and PFS (C) in patients undergoing resection for conventional cranial base chondrosarcoma. Vertical hash marks indicate censored data. EMC = extraskeletal myxoid chondrosarcoma; OS = overall survival. Figure is available in color online only.

tary Fig. S1a). Survival curves broken down by the extent of resection, however, showed no statistically significant relationship between the extent of resection and tumor progression (Supplementary Fig. S1). Similarly, we were unable to find a clear statistically significant relationship between progression and tumor grade, Ki-67 percentage, sex, and administration of postoperative radiation therapy in this 41-patient cohort (Supplementary Figs. S2a, c, and $\mathrm{d}$ and $\mathrm{S} 4$ ), though postoperative radiation may reflect a trend toward significance $(\mathrm{p}=0.14)$. Eighteen of $41 \mathrm{pa}-$ 
TABLE 1. Features of patients with cranial base chondrosarcoma

\begin{tabular}{|c|c|}
\hline Feature & Value (\%) \\
\hline \multicolumn{2}{|l|}{ Pathology } \\
\hline Conventional & $41 / 43(95.3 \%)$ \\
\hline Mesenchymal & $1 / 43(2.3 \%)$ \\
\hline Extraskeletal myxoid & $1 / 43(2.3 \%)$ \\
\hline \multicolumn{2}{|l|}{ Sex } \\
\hline Female & $26 / 41(63.4 \%)$ \\
\hline Male & $15 / 41(36.6 \%)$ \\
\hline Mean age, yrs & 51.5 \\
\hline Mean follow-up, mos & 53 \\
\hline \multicolumn{2}{|l|}{ Extent of resection } \\
\hline$>90 \%$ & $37 / 41(90.2 \%)$ \\
\hline$>95 \%$ & $33 / 41(80.5 \%)$ \\
\hline Gross-total resection & $25 / 41(61.0 \%)$ \\
\hline Initial surgery elsewhere & $7 / 41(17.0 \%)$ \\
\hline Preop RT & $2 / 41(4.9 \%)$ \\
\hline Postop RT & $18 / 41(43.9 \%)$ \\
\hline \multicolumn{2}{|l|}{ Initial approach } \\
\hline Endoscopic endonasal & $39 / 41(95.1 \%)$ \\
\hline Open microsurgical & $0 / 41(0 \%)$ \\
\hline Combination EEA + open & $2 / 41(4.9 \%)$ \\
\hline \multicolumn{2}{|l|}{ Event } \\
\hline Progression & $12 / 41(29.2 \%)$ \\
\hline Death & $5 / 41(12.2 \%)$ \\
\hline
\end{tabular}

$\mathrm{RT}=$ radiation treatment.

tients received postoperative radiation therapy (median age 51 years), and 23 of 41 patients did not (median age 61) ( $p=0.13$, Wilcoxon test). For the 18 patients who underwent postoperative radiation therapy, 11 patients had proton beam radiotherapy (all $>70$ Gy except one who had $63 \mathrm{~Gy}$ ), 4 patients had photon radiotherapy (15- to 18Gy median margin dose), and 3 patients were not documented. Twenty-five of 41 patients underwent gross-total resections, but this was not significantly associated with receiving postoperative radiation therapy $(\mathrm{p}=0.34$, chisquare test).

\section{Identifying Novel Variables Associated With Tumor Progression}

We next sought to identity novel variables associated with tumor progression in patients with cranial base chondrosarcomas. We performed a univariate analysis by tumor location and neuroimaging features, which revealed that 4 of these variables were statistically significant $(\mathrm{p}$ $<0.1$ ), which included 2 locations (the anterior fossa/orbit and the sublacerum region) and 2 radiological features (size and number of major arteries encased) (Supplementary Fig. S3, Table 3). To determine which variables were independently associated with PFS, we next performed a multivariate regression analysis using the 5 variables found to be statistically significant $(\mathrm{p}<0.1)$ : patient age,
TABLE 2. Summary of PFS and overall survival in patients who underwent surgery for cranial base chondrosarcoma

\begin{tabular}{lcccc}
\hline \multirow{2}{*}{ Survival } & \multicolumn{4}{c}{ Percentage of Patients } \\
\cline { 2 - 5 } & 1 Year & 3 Years & 5 Years & 10 Years \\
\hline PFS & $94.2 \%$ & $82.4 \%$ & $67.5 \%$ & $57.9 \%$ \\
\hline Overall survival & $97.4 \%$ & $89.6 \%$ & $80.2 \%$ & $80.2 \%$ \\
\hline
\end{tabular}

anterior fossa/orbit location, sublacerum location, tumor size, and major artery encasement. This revealed that only patient age and major artery encasement were independently associated with PFS ( $<<0.05)$ (Table 4). Of note, arterial encasement did not significantly affect the extent of resection. In addition, patients with 3-4 vessels encased were not more likely to undergo postoperative radiotherapy $(\mathrm{p}=0.78$, chi-square test).

\section{Building a Preoperative Risk Classifier to Predict Tumor Progression in Cranial Base Chondrosarcoma}

Like patient age, we noted that arterial encasement was a powerful predictor of PFS in our cohort. When we analyzed tumor progression in patients whose tumors encased 3-4 major arteries, we discovered there was a dramatic reduction in median PFS - from more than 10 years to less than 2 years (Fig. 3). Because age and arterial encasement were strongly correlated with PFS, we next wondered whether generating a risk stratification system based on these two variables could be predictive of tumor progression.

To generate a risk stratification system, we assigned each patient points based on the two independent variables that showed significance in multivariate regression: age and the number of major vessels encased. We gave 1 point for those patients whose age was $\geq 35$ years and 1 point for tumors that encased 3 or 4 vessels (Fig. 4A). This system categorized patients into 3 subgroups: a low-risk group (0 points), an intermediate-risk group (1 point), and a high-risk group (2 points). High-risk patients had a median PFS of less than 2 years, intermediate-risk patients had a median PFS of more than 10 years, and low-risk patients did not have tumor progression in our cohort (Fig. 4B). Therefore, we conclude that this simple system based on variables known preoperatively is a quick and useful method to estimate the prognosis in patients with cranial base chondrosarcomas.

\section{Discussion}

Cranial base chondrosarcomas are formidable lesions to treat surgically because of our reliance on resection as a primary treatment modality and the lesions' propensity to involve critical neurovascular structures. Given the potential for morbidity and expertise required for the resection of these challenging tumors, we sought to create a risk classifier that could be used preoperatively to predict tumor progression. Such a tool, if available preoperatively, could inform our surgical goals and guide postoperative management and adjunctive treatment. We found that patient age and major artery encasement are two variables 

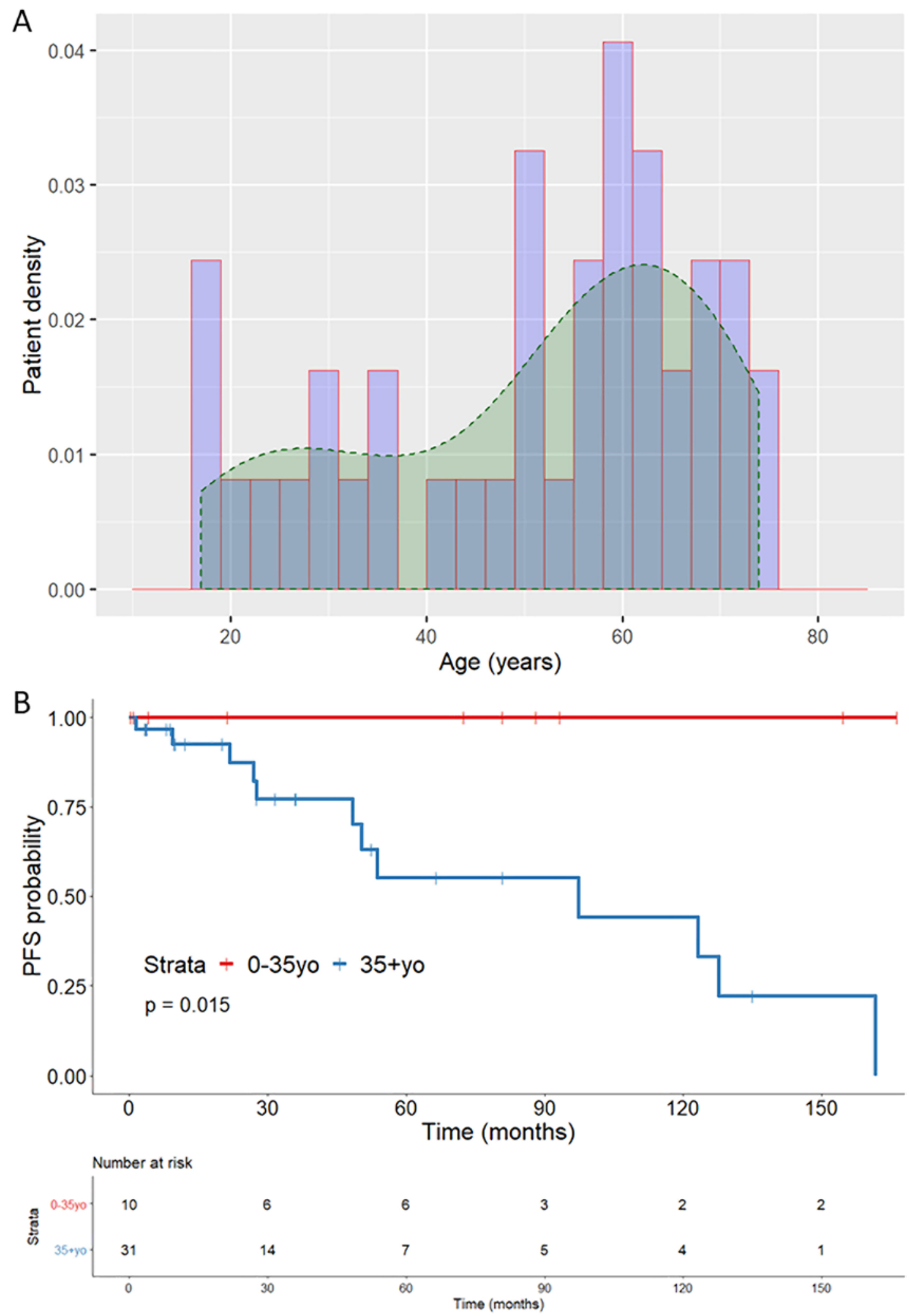

FIG. 2. Analysis of age in patients with cranial base chondrosarcoma. A: Histogram with trendline showing distribution of patients by age. B: Kaplan-Meier curves of PFS comparing youngest quartile by age of patients to remainder of the cohort. Vertical hash marks indicate censored data. Figure is available in color online only. 
TABLE 3. Univariate analysis of location and radiographic features in patients who underwent surgery for cranial base chondrosarcoma

\begin{tabular}{lll}
\hline \multicolumn{1}{c}{ Variable } & $\mathrm{HR}(95 \% \mathrm{Cl})$ & $\mathrm{p} \mathrm{Value}$ \\
\hline Location & & \\
\hline Anterior fossa/orbit & $3.8(1.0-15)$ & 0.057 \\
\hline Cavernous sinus & $2.9(0.8-11)$ & 0.12 \\
\hline Posterior clinoid & $2.8(0.7-12)$ & 0.16 \\
\hline Sublacerum & $0.34(0.1-1.1)$ & 0.063 \\
\hline Radiological parameter & & \\
\hline Size & $1.7(1.1-2.7)$ & 0.025 \\
\hline Artery encasement & $2.3(1.3-4.3)$ & 0.0054 \\
\hline Intradural tumor & $1.2(0.51-2.7)$ & 0.71 \\
\hline Gadolinium enhancement & $1.8(0.47-6.9)$ & 0.39 \\
\hline
\end{tabular}

known preoperatively that can strongly classify patients into low-, intermediate-, and high-risk groups with dramatic differences in median PFS.

Surgical decision-making for chondroid tumors is complex. Chondroid tumors have been shown to be the highest risk category for vascular injury during endoscopic endonasal resections. ${ }^{9}$ Thus, for patients in lower risk categories, some patients and surgeons may choose a planned subtotal resection strategy rather than to proceed with attempted gross-total resection, which at our institution usually includes performing a balloon test occlusion, skeletonizing the carotid artery, and potentially adding an endoscopic contralateral transmaxillary approach..$^{21} \mathrm{On}$ the other hand, an older patient with a significant number of arteries encased would be considered higher risk surgically and would therefore lead us to undertake a more conservative approach. However, in light of these findings, this must now be balanced with the higher risk of progression and resultant difficulty in tumor control.

Our analysis also revealed surprisingly that no statistically significant relationship between PFS and tumor grade or PFS and the extent of resection was apparent in our series. Therefore, our results suggest that patient age and arterial encasement may be used to risk stratify patients with greater utility than surgical results (histopathological analysis and extent of resection). We now consider performing postoperative radiotherapy for older patients with at least 3 arterial vessels encased by the tumor and may withhold it for young patients with little or no encasement.

\section{Limitations}

Limitations of this study include the single-institution, retrospective nature of the patient cohort with associated referral and institutional biases. A second limitation is the long time interval studied (2004-2018), as endonasal skull base surgery was in its infancy during the early years, and there have been significant advances during this time period that might influence the variables studied, such as the extent of resection. Third, as our cohort was treated predominantly via endonasal approaches with a relatively
TABLE 4. Multivariate regression in patients who underwent surgery for cranial base chondrosarcoma

\begin{tabular}{lll}
\hline \multicolumn{1}{c}{ Variable } & $\mathrm{HR}(95 \% \mathrm{Cl})$ & $\mathrm{p} \mathrm{Value}$ \\
\hline Age & $1.01-1.20$ & $\mathbf{0 . 0 3 4}$ \\
\hline Sublacerum & $0.049-1.50$ & 0.18 \\
\hline Anterior fossa/orbit & $0.26-15.2$ & 0.51 \\
\hline Size & $0.41-1.80$ & 0.71 \\
\hline Artery encasement & $1.06-8.20$ & $\mathbf{0 . 0 3 8}$ \\
\hline
\end{tabular}

Boldface type indicates statistical significance $(p<0.05)$.

high rate of gross-total resections, this grading system may be most relevant for patients in whom similar results are achieved. Fourth, our results will need to be validated on an external data set to determine their generalizability.

\section{Extent of Resection}

While the extent of resection has been reported as being correlated with PFS by some ${ }^{23}$ but not all groups, ${ }^{26}$ we did not find as strong an association in our cohort. This may be due to the rarity of cranial base chondrosarcomas and having only 41 patients in our single-institution study. There is, of course, a potential bias in any retrospective series toward gross-total resection in more clinically aggressive tumors and a more conservative resection if the tumor is asymptomatic; nevertheless, subtotal resection would likely be more the result of anatomical limitations and learning curve. Our rate of gross-total resection (61\%) is comparable to those found in other studies from academic centers (36\%-67\%). ${ }^{15,22,25,26}$ Since one high-volume center reported a strong trend toward an association between gross-total resection and improved PFS in patients with conventional cranial base chondrosarcomas, ${ }^{23}$ a meta-analysis and/or multiinstitutional study may be useful to determine if such an association would be even stronger with a larger number of patients. Similarly, residual tumor volume postoperatively has also been shown to correlate inversely with improved tumor control. ${ }^{10,31}$ Correspondingly, we anticipate that surgical advances in skull base approaches, such as the contralateral transmaxillary approach, will increasingly provide safe maximal exposures to locations frequently involved by chondrosarcomas, including the petrous apex,$^{21}$ and may improve outcomes.

\section{Grade}

In our cohort, 16 patients had grade 1 chondrosarcomas, 21 patients had grade 2 chondrosarcomas, no patients had grade 3 chondrosarcomas, and 4 patients did not have a grade recorded in the pathology report. Grading of chondrosarcoma is notoriously difficult histopathologically, as this relies on a number of subjective histological criteria, including nuclear pleomorphism, cellularity, degree of bone entrapment, and degree of mucoid matrix. Even among specialists in bone tumor pathology, interobserver variability is surprisingly high.? This may cause discrepancies in the literature in determining the statistical power of using grades to predict outcomes from different institutions. ${ }^{23,25}$ As a result, the risk classifier proposed here could 


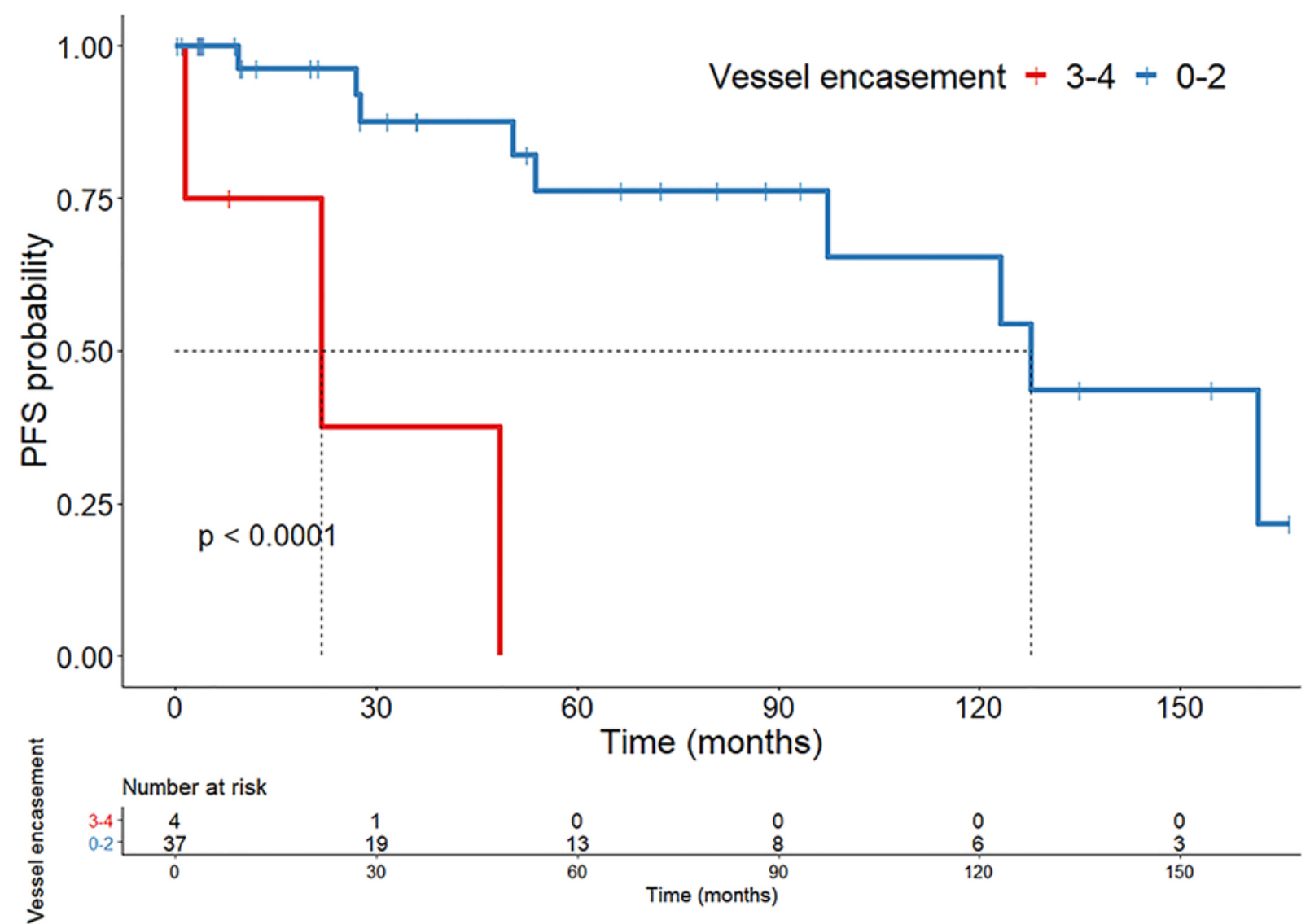

FIG. 3. Multivariate analysis of data obtained in cranial base chondrosarcoma patients. The Kaplan-Meier curve shows marked reduction in PFS when 3-4 major arteries are encased by tumor. Vertical hash marks indicate censored data. Figure is available in color online only.

provide better guidance for treatment options, including adjuvant radiation therapy.

\section{Age}

Age has been inversely associated with tumor progression, for both axial and appendicular chondrosarcomas ${ }^{2,8,18,29}$ and cranial base chondrosarcomas. ${ }^{13}$ We found that younger patients (age $<35$ years) had a greatly improved long-term outcome compared to older patients. This finding is reminiscent of similar observations in patients with gliomas: younger patients were shown to have improved survival, which was later explained by the presence of a mutation in $I D H$ that defines a different glioma subtype. ${ }^{20}$ In the case of chondrosarcoma, the different outcomes with respect to age may similarly reflect different biological etiologies for tumor subtypes that remain enigmatic since they appear histologically indistinguishable.

\section{Arterial Encasement}

To our knowledge, this study is the first to reveal a link between major artery encasement and tumor progression in cases of chondrosarcoma. Arterial encasement, even in expert hands, represents a barrier to maximal resection, which often requires expanded or staged approaches to achieve adequate resection. Furthermore, tumors may infiltrate surrounding the soft tissue and adventitia of blood vessels, allowing for microscopic residual disease postoperatively that cannot be detected on MRI. However, given the lack of correlation between the extent of resection and PFS, it is unlikely that arterial encasement is merely a marker of resectability. Rather, it may represent the biological nature and invasive phenotype of the tumor. Since patients with 3 or 4 major arteries encased have a much worse outcome (median PFS $<2$ years), we recommend adjunctive radiotherapy upfront or close monitoring for any recurrence so that radiation can be administered as early as possible, given that this has been associated with improved PFS in some studies., ${ }^{3,23}$ We carefully select patients for radiation treatment, because many of the tumors they harbor are indolent and radiation can lead to complications, including sensorineural hearing loss. ${ }^{17,26}$

\section{Conclusions}

Cranial base chondrosarcomas are among the most challenging skull base tumors to resect fully given their propensity to involve major arteries and cranial nerves. Here, we have proposed a simple risk classifier based on two variables that dramatically impact PFS and are known preoperatively: patient age and the number of ma- 

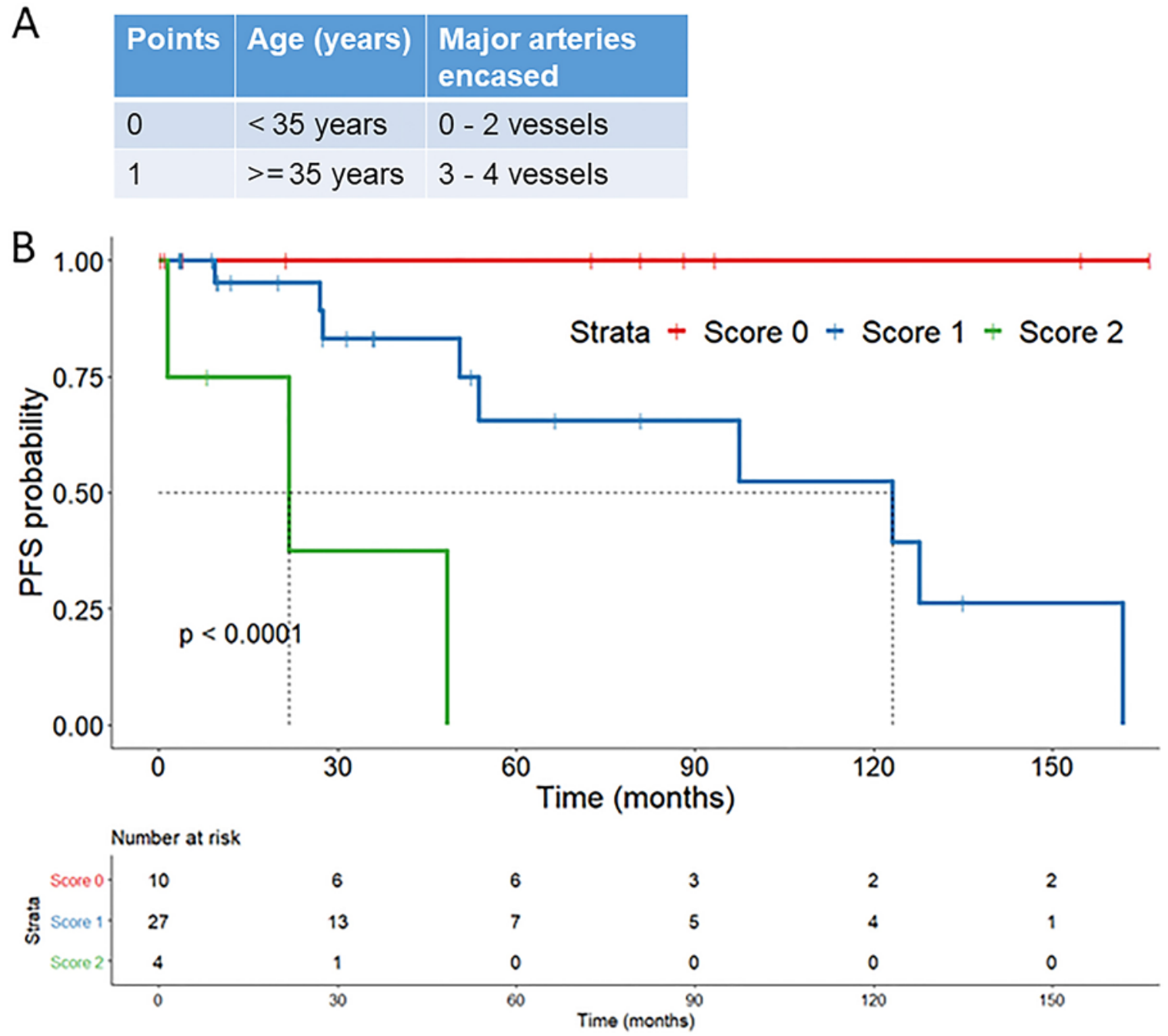

FIG. 4. Risk classifier model for patients with cranial base chondrosarcoma. A: Point assignment system gives 1 point for patients $\geq 35$ years of age and 1 point if 3-4 major arteries are encased by the tumor. B: Kaplan-Meier survival estimates for patients with 0,1 , and 2 points. Vertical hash marks indicate censored data. Figure is available in color online only.

jor arteries encased by the tumor. This tool stratifies patients into 3 categories, with high-risk patients $(10 \%$ of our patients) having a 1.8-year median PFS, intermediaterisk patients (68\% of patients) having a 10.3 -year median PFS, and low-risk patients ( $22 \%$ of patients) having no disease progression. Our risk classifier can inform intraoperative decision-making and can guide postoperative management.

\section{References}

1. Andreou D, Ruppin S, Fehlberg S, Pink D, Werner M, Tunn PU: Survival and prognostic factors in chondrosarcoma: results in 115 patients with long-term follow-up. Acta Orthop 82:749-755, 2011

2. Bergh P, Gunterberg B, Meis-Kindblom JM, Kindblom LG: Prognostic factors and outcome of pelvic, sacral, and spinal chondrosarcomas: a center-based study of 69 cases. Cancer 91:1201-1212, 2001

3. Bloch OG, Jian BJ, Yang I, Han SJ, Aranda D, Ahn BJ, et al:
A systematic review of intracranial chondrosarcoma and survival. J Clin Neurosci 16:1547-1551, 2009

4. Burkey BB, Hoffman HT, Baker SR, Thornton AF, McClatchey KD: Chondrosarcoma of the head and neck. Laryngoscope 100:1301-1305, 1990

5. Crockard HA, Cheeseman A, Steel T, Revesz T, Holton JL, Plowman N, et al: A multidisciplinary team approach to skull base chondrosarcomas. J Neurosurg 95:184-189, 2001

6. Dorfman HD, Czerniak B: Bone cancers. Cancer 75 (1 Suppl):203-210, 1995

7. Eefting D, Schrage YM, Geirnaerdt MJ, Le Cessie S, Taminiau AH, Bovée JV, et al: Assessment of interobserver variability and histologic parameters to improve reliability in classification and grading of central cartilaginous tumors. Am J Surg Pathol 33:50-57, 2009

8. Fromm J, Klein A, Baur-Melnyk A, Knösel T, Lindner L, Birkenmaier C, et al: Survival and prognostic factors in conventional central chondrosarcoma. BMC Cancer 18:849, 2018

9. Gardner PA, Tormenti MJ, Pant H, Fernandez-Miranda JC, Snyderman CH, Horowitz MB: Carotid artery injury during endoscopic endonasal skull base surgery: incidence and 
outcomes. Neurosurgery 73 (2 Suppl Operative):ons261ons270, 2013

10. Gatfield ER, Noble DJ, Barnett GC, Early NY, Hoole ACF, Kirkby NF, et al: Tumour volume and dose influence outcome after surgery and high-dose photon radiotherapy for chordoma and chondrosarcoma of the skull base and spine. Clin Oncol (R Coll Radiol) 30:243-253, 2018

11. Henderson ED, Dahlin DC: Chondrosarcoma of bone-a study of two hundred and eighty-eight cases. J Bone Joint Surg Am 45:1450-1458, 1963

12. Iyer A, Kano H, Kondziolka D, Liu X, Flickinger JC, Lunsford LD: Postsurgical management strategies in patients with skull base chondrosarcomas. CNS Oncol 2:203-208, 2013

13. Jones PS, Aghi MK, Muzikansky A, Shih HA, Barker FG II, Curry WT Jr: Outcomes and patterns of care in adult skull base chondrosarcomas from the SEER database. J Clin Neurosci 21:1497-1502, 2014

14. Lee SY, Lim YC, Song MH, Seok JY, Lee WS, Choi EC: Chondrosarcoma of the head and neck. Yonsei Med J 46:228-232, 2005

15. Li D, Weng JC, Zhang GJ, Hao SY, Tang J, Zhang LW, et al: Proposed treatment paradigm for intracranial chondrosarcomas based on multidisciplinary coordination. World Neurosurg 109:e517-e530, 2018

16. Ma X, Meng G, Wang K, Li D, Wang L, Li H, et al: The differences between intracranial mesenchymal chondrosarcoma and conventional chondrosarcoma in clinical features and outcomes. World Neurosurg 122:e1078-e1082, 2019

17. Mattke M, Vogt K, Bougatf N, Welzel T, Oelmann-Avendano $\mathrm{J}$, Hauswald H, et al: High control rates of proton- and carbon-ion-beam treatment with intensity-modulated active raster scanning in 101 patients with skull base chondrosarcoma at the Heidelberg Ion Beam Therapy Center. Cancer 124:2036-2044, 2018

18. Nota SP, Braun Y, Schwab JH, van Dijk CN, Bramer JA: The identification of prognostic factors and survival statistics of conventional central chondrosarcoma. Sarcoma 2015:623746, 2015

19. Oghalai JS, Buxbaum JL, Jackler RK, McDermott MW: Skull base chondrosarcoma originating from the petroclival junction. Otol Neurotol 26:1052-1060, 2005

20. Parsons DW, Jones S, Zhang X, Lin JC, Leary RJ, Angenendt $\mathrm{P}$, et al: An integrated genomic analysis of human glioblastoma multiforme. Science 321:1807-1812, 2008

21. Patel CR, Wang EW, Fernandez-Miranda JC, Gardner PA, Snyderman CH: Contralateral transmaxillary corridor: an augmented endoscopic approach to the petrous apex. J Neurosurg 129:211-219, 2018

22. Raza SM, Gidley PW, Kupferman ME, Hanna EY, Su SY, DeMonte F: Site-specific considerations in the surgical management of skull base chondrosarcomas. Oper Neurosurg (Hagerstown) 14:611-619, 2018

23. Raza SM, Gidley PW, Meis JM, Grosshans DR, Bell D, DeMonte F: Multimodality treatment of skull base chondrosarcomas: the role of histology specific treatment protocols. Neurosurgery 81:520-530, 2017

24. Ruark DS, Schlehaider UK, Shah JP: Chondrosarcomas of the head and neck. World J Surg 16:1010-1016, 1992

25. Samii A, Gerganov V, Herold C, Gharabaghi A, Hayashi N, Samii M: Surgical treatment of skull base chondrosarcomas. Neurosurg Rev 32:67-75, 2009
26. Simon F, Feuvret L, Bresson D, Guichard JP, El Zein S, Bernat AL, et al: Surgery and protontherapy in Grade I and II skull base chondrosarcoma: a comparative retrospective study. PLoS One 13:e0208786, 2018

27. Unni KK, Dahlin DC: Dahlin's Bone Tumors: General Aspects and Data on 11,087 Cases, ed 5. Philadelphia: Lippincott-Raven, 1996

28. van Oosterwijk JG, Anninga JK, Gelderblom H, CletonJansen AM, Bovée JV: Update on targets and novel treatment options for high-grade osteosarcoma and chondrosarcoma. Hematol Oncol Clin North Am 27:1021-1048, 2013

29. van Praag Veroniek VM, Rueten-Budde AJ, Ho V, Dijkstra PDS, Fiocco M, van de Sande MAJ: Incidence, outcomes and prognostic factors during 25 years of treatment of chondrosarcomas. Surg Oncol 27:402-408, 2018

30. Vaz-Guimaraes F, Fernandez-Miranda JC, Koutourousiou M, Hamilton RL, Wang EW, Snyderman CH, et al: Endoscopic endonasal surgery for cranial base chondrosarcomas. Oper Neurosurg (Hagerstown) 13:421-434, 2017

31. Weber DC, Badiyan S, Malyapa R, Albertini F, Bolsi A, Lomax AJ, et al: Long-term outcomes and prognostic factors of skull-base chondrosarcoma patients treated with pencil-beam scanning proton therapy at the Paul Scherrer Institute. Neuro Oncol 18:236-243, 2016

32. Weber DC, Malyapa R, Albertini F, Bolsi A, Kliebsch U, Walser M, et al: Long term outcomes of patients with skullbase low-grade chondrosarcoma and chordoma patients treated with pencil beam scanning proton therapy. Radiother Oncol 120:169-174, 2016

\section{Disclosures}

The authors report no conflict of interest concerning the materials or methods used in this study or the findings specified in this paper.

\section{Author Contributions}

Conception and design: Venteicher, McDowell. Acquisition of data: Venteicher, McDowell, Goldschmidt. Analysis and interpretation of data: Venteicher, McDowell, Wang, Snyderman. Drafting the article: Venteicher. Critically revising the article: Gardner, Venteicher, McDowell, Wang, Snyderman. Reviewed submitted version of manuscript: all authors. Approved the final version of the manuscript on behalf of all authors: Gardner. Statistical analysis: Venteicher. Study supervision: Gardner, Venteicher.

\section{Supplemental Information \\ Online-Only Content}

Supplemental material is available with the online version of the article.

Supplementary Figs. S1-S4. https://thejns.org/doi/suppl/ 10.3171/2019.10.JNS191672.

\section{Correspondence}

Paul A. Gardner: University of Pittsburgh Medical Center, Pittsburgh,PA.gardpa@upmc.edu. 